\title{
Efficient Removal of Methylene Blue from Aqueous Solutions Using a High Specific Surface Area Porous Carbon Derived from Soybean Dreg
}

\author{
Zhiwei Ying ${ }^{1,2}$, Lu Huang ${ }^{1,2}$, Lili Ji ${ }^{3}$, He Li ${ }^{1,2, * \mathbb{C}}$, Xinqi Liu ${ }^{1,2, *}$, Chi Zhang ${ }^{1,2}$, Jian Zhang ${ }^{1,2} \mathbb{D}$ and \\ Guofu Yi ${ }^{1,2}$ D
}

check for

updates

Citation: Ying, Z.; Huang, L.; Ji, L.; Li, H.; Liu, X.; Zhang, C.; Zhang, J.; Yi, G. Efficient Removal of Methylene Blue from Aqueous Solutions Using a High Specific Surface Area Porous Carbon Derived from Soybean Dreg. Materials 2021, 14, 1754. https:// doi.org/10.3390/ma14071754

Academic Editor:

Agata Jakóbik-Kolon

Received: 10 February 2021

Accepted: 31 March 2021

Published: 2 April 2021

Publisher's Note: MDPI stays neutral with regard to jurisdictional claims in published maps and institutional affiliations.

Copyright: (c) 2021 by the authors. Licensee MDPI, Basel, Switzerland. This article is an open access article distributed under the terms and conditions of the Creative Commons Attribution (CC BY) license (https:// creativecommons.org/licenses/by/ $4.0 /)$.
1 National Soybean Processing Industry Technology Innovation Center, Beijing Technology and Business University (BTBU), Beijing 100048, China; yingzhiwei0906@163.com (Z.Y.); huanglulu1119@163.com (L.H.); cauzhangchi@163.com (C.Z.); tsnpzhj@163.com (J.Z.); yiguofu0203@163.com (G.Y.)

2 Beijing Advanced Innovation Center for Food Nutrition and Human Health, Beijing Engineering and Technology Research Center of Food Additives, Beijing Technology and Business University (BTBU), Beijing 100048, China

3 Institute of Innovation and Application, Zhejiang Ocean University, Zhoushan 316022, China; jll-gb@163.com

* Correspondence: lihe@btbu.edu.cn (H.L.); liuxinqi@btbu.edu.cn (X.L.)

\begin{abstract}
Porous carbon material with high specific surface area was prepared from soybean dreg by a simple and effective two-step method (high temperature pyrolysis and activation). The structural characteristics of the synthesized carbon were evaluated by Brunauer-Emmett-Teller (BET), $\mathrm{N}_{2}$ adsorption/desorption measurements/techniques, an elemental analyzer (EA), scanning electron microscopy equipped with energy dispersive $\mathrm{X}$-ray spectroscopy (SEM-EDS), transmission electron microscopy (TEM), an X-ray diffractometer (XRD), Raman spectroscopy (Raman), a Fourier transform infrared spectrometer (FTIR), and X-ray photoelectron spectroscopy (XPS). The specific surface area of SDB-6-K was $2786 \mathrm{~m}^{2} \mathrm{~g}^{-1}$, the pore volume was $2.316 \mathrm{~cm}^{3} \mathrm{~g}^{-1}$, and the average pore size was $3.326 \mathrm{~nm}$. The high specific surface area and effective functional groups of carbon material promoted the adsorption of methylene blue. The maximum adsorption capacity of SDB-6-K to methylene blue was $2636 \mathrm{mg} \mathrm{g}^{-1}$ at $318 \mathrm{~K}$. The adsorption kinetic and isotherm data were most suitable for pseudo-second-order and Langmuir equations. The results showed that the adsorbent had excellent adsorptive ability and had good practical application potential in the field of dye wastewater treatment in the future.
\end{abstract}

Keywords: soybean dreg; porous carbon; activation; adsorption; dye

\section{Introduction}

Organic dyes are widely used in food, textile, papermaking, pharmaceuticals, plastics, and cosmetics industries, and the discharge of dye wastewater has also increased during the production and processing process as economies develop dramatically quickly [1]. Generally, dye wastewater contains a variety of organic compounds, including phenyl, amino, azo, etc., has the characteristics of high toxicity, deep color, difficult biodegradation, strong photolysis, and oxidation resistance [2], and has become one of the main harmful industrial wastewaters [3]. Among dyes, methylene blue is a representative compound of water-soluble dyes and is a cationic dye that is widely used. Its long-term exposure can cause vomiting, nausea, anemia, and hypertension. If dye wastewater cannot be treated properly and discharged directly, it will destroy the ecological environment and affect human health. Therefore, a prominent environmental protection problem has been how to effectively treat dye wastewater to reach the discharge standard [4]. Several common methods have been developed to remove these organic dyes, for instance, adsorption [5], chemical oxidation [6], photochemical degradation [7,8], and ultrasonic degradation [9], among which the adsorption method is one of the most valuable methods for research and 
application owing to its easy operation, environmental friendliness, low cost, lower energy consumption, superior stability, high efficiency, and so on [1,10].

For the past few years, carbon materials have been favored by researchers because of their unique internal structures, excellent performance, and extensive application prospects [11]. In the current research, carbon materials with different structural characteristics have been used as effective adsorbents to remove organic dyes, including activated carbon [12], mesoporous carbon [13], and carbon nanotubes (CNTs) [14], among which activated carbon has become one of the most concerned adsorbents for its structural characteristics and excellent adsorption capacity. However, researchers have been looking for low-cost adsorbents with promising applications to replace activated carbon, on account of its high cost and limited use [15]. Nowadays, agricultural waste material has become one of the research hotspots as a precursor of carbon materials in dye wastewater treatment, owning to its advantages of high carbon content, renewability, and low cost, and these materials, including coffee grounds [11], popcorn [16], pineapple crown leaves [17], grape pulp, wheat bran [18], waste mushroom matrix [19], and orange peel [20] have been prepared into various biomass carbon adsorbents for removing organic dye from aqueous solution.

Soybean is a major cash crop in China [21], the annual production of which is up to 16 million tons. Soybean dreg (SD) is a by-product of soybean protein and soybean oil separation or tofu and soybean milk processing, which is rich in dietary fiber and protein. However, to the best of our knowledge, soybean dreg has not been effectively utilized except for animal feed, plant fertilizer, or direct waste [22] because of its rough taste, high moisture content, difficult storage, and low energy content $[23,24]$.

The aim of this work was to study organic dye adsorption performance of porous carbon material with high specific surface area obtained from soybean dreg by pyrolysis and $\mathrm{KOH}$ activation. The adsorbents were characterized by Brunauer-Emmett-Teller (BET), $\mathrm{N}_{2}$ adsorption/desorption measurements/techniques, an elemental analyzer (EA), scanning electron microscopy equipped with energy dispersive X-ray spectroscopy (SEMEDS), transmission electron microscopy (TEM), an X-ray diffractometer (XRD), Raman spectroscopy (Raman), a Fourier transform infrared spectrometer (FTIR), and X-ray photoelectron spectroscopy (XPS). The adsorption kinetics and thermodynamics performances of as-prepared samples to remove methylene blue (MB) were investigated. Then the adsorption performances of single dye and mixed dyes on as-prepared sample were also studied.

\section{Materials and Methods}

\subsection{Materials}

SD was provided by Shandong Yuxin Biotechnology Co., Ltd., Shandong Province. The soybean dreg was dried at $105^{\circ} \mathrm{C}$ for $48 \mathrm{~h}$ in a vacuum oven (GZX-9030 MBE, Shanghai Boxun Industrial Co., Ltd., Shanghai, China).

Commercial activated carbon (AC) was purchased from Chengde Xingyuan Activated Carbon Co. LTD. Methyl orange (MO) and crystal violet (CV) were purchased from Tianjin Fuchen Chemical Reagent Factory. Potassium hydroxide (KOH), methylene blue (MB), rhodamine $\mathrm{B}(\mathrm{RhB})$, and hydrochloric acid $(\mathrm{HCl}, 37 \mathrm{wt} \%)$ were purchased from Sinopharm Chemical Reagent Co., Ltd. (Shanghai, China) All chemical reagents were of analytical grade and used directly without further purification.

\subsection{Preparation of Porous Carbon Materials}

A total of $30 \mathrm{~g}$ of dried soybean dreg powder was carbonized in a tubular furnace under nitrogen flow $\left(250 \mathrm{~mL} \mathrm{~min}^{-1}\right)$ up to $500,600,700$, and $800^{\circ} \mathrm{C}$, respectively, at a rate of $10^{\circ} \mathrm{C} \mathrm{min}{ }^{-1}$, and the final constant temperature was held for $60 \mathrm{~min}$.

The obtained pre-carbonized sample was mixed with $\mathrm{KOH}$ in the mass ratio $(\mathrm{KOH}$ : pre-carbonized materials $=4: 1(\mathrm{~m} / \mathrm{m})$ ) and ground evenly. Then it was put into a corundum crucible. Under the condition of nitrogen flow rate $\left(250 \mathrm{~mL} \mathrm{~min}^{-1}\right)$, the mixture sample 
was activated to $800^{\circ} \mathrm{C}$ in a tubular furnace, and the heating rate was $10^{\circ} \mathrm{C} \mathrm{min}{ }^{-1}$. Finally, the constant temperature was maintained for $90 \mathrm{~min}$. When the temperature dropped to room temperature, the as-prepared samples were placed in a $5 \mathrm{wt} \% \mathrm{HCl}$ solution and continuously stirred for $24 \mathrm{~h}$, then washed with a large amount of distilled water until the $\mathrm{pH}$ of the filtrate was about 7 , and further dried at $105^{\circ} \mathrm{C}$ for $24 \mathrm{~h}$. The as-prepared samples were denoted as SDB-X-K $(X=5,6,7$, and 8 , referring to the pre-carbonization temperature of $500,600,700$, and $800{ }^{\circ} \mathrm{C}$, respectively).

\subsection{Characterization of Porous Carbon Materials}

The pore characteristics was performed at $77 \mathrm{~K}$ on a nitrogen adsorption apparatus (BET, Quantachrome Autosorb-iQ, Boynton Beach, FL, USA). The weight ratio of the elements $\mathrm{C}, \mathrm{H}, \mathrm{O}, \mathrm{N}$, and $\mathrm{S}$ were analyzed by an elemental analyzer (Elementar Vario EL III, Hanau, Germany). In order to observe the surface state of as-prepared samples, the images of microstructure and morphology were performed by a scanning electron microscope (SEM; JEOL JSM-6700F, Tokyo, Japan) equipped with energy dispersive Xray spectroscopy (EDS), and a transmission electron microscope (TEM; JEOL JEM-2100F). The phase composition and crystal structure were recorded by X-ray diffraction (Rigaku Ultima IV, Tokyo, Japan) in the range of $10-80^{\circ}$ and Raman spectroscopy (Raman, Bruker Optics SENTERRA, Ettlingen, Germany, excitation-beam wavelength: $532 \mathrm{~nm}$ ). The surface properties were analyzed by means of X-ray photoelectron spectroscopy (XPS; Thermo Scientific Escalab 250Xi, Waltham, MA, USA). In this paper, the surface chemical functional groups were determined by Fourier transform infrared spectrometry (FTIR; SHIMADZU Type 2000, Tokyo, Japan).

\subsection{Adsorption of Organic Dyes}

A total of $0.025 \mathrm{~g}$ of as-prepared sample was added to each of three Erlenmeyer flasks with $25 \mathrm{~mL}$ of 1000, 2000, and $3000 \mathrm{mg} \mathrm{L}^{-1} \mathrm{MB}$ aqueous solutions, which were placed in a water-bathing constant temperature vibrator (WE-3, Tianjin Ounuo Instrument Co., Ltd., Tianjin, China) at $150 \mathrm{rpm}$ for $2 \mathrm{~h}$ at $298 \mathrm{~K}$. After adsorption, solid-liquid separation was carried out by centrifugation at $4000 \mathrm{rpm}$ for $10 \mathrm{~min}$; then the supernatant was filtered by 0.22 um filter, and its adsorption value was determined using an ultraviolet spectrophotometer (UV-vis, Agilent Cary-60, Palo Alto, CA, USA) at $664 \mathrm{~nm}$, which is the maximum adsorption wavelength of MB. The adsorption amount $\mathrm{Q}\left(\mathrm{mg} \mathrm{g}^{-1}\right)$ and removal efficiency R (\%) of MB were, respectively, calculated according to Equations (1) and (2).

$$
\begin{gathered}
\mathrm{Q}\left(\mathrm{mg} \mathrm{g}^{-1}\right)=\frac{\left(\mathrm{C}_{0}-\mathrm{C}\right) \mathrm{V}}{\mathrm{m}} \\
\mathrm{R}(\%)=\frac{\mathrm{C}_{0}-\mathrm{C}}{\mathrm{C}_{0}} \times 100 \%
\end{gathered}
$$

where $\mathrm{Q}\left(\mathrm{mg} \mathrm{g}^{-1}\right)$ is the amount of dye adsorbed on the prepared sample, $\mathrm{C}_{0}\left(\mathrm{mg} \mathrm{L}^{-1}\right)$ is the initial dye solution concentration, $\mathrm{C}\left(\mathrm{mg} \mathrm{L}^{-1}\right)$ is the concentration of dye solution after adsorption $\left(\mathrm{mg} \mathrm{L}^{-1}\right), \mathrm{V}(\mathrm{L})$ is the volume of dye solution, $\mathrm{m}(\mathrm{g})$ is the mass of adsorbent used, and $\mathrm{R}(\%)$ is the removal efficiency of dye.

\subsection{Study on Adsorption Kinetics and Thermodynamics}

In the kinetic experiments, $0.025 \mathrm{~g}$ SDB-6-K was used to adsorb $25 \mathrm{~mL}$ of each of 1000 , 2000, and $3000 \mathrm{mg} \mathrm{L}^{-1} \mathrm{MB}$ solutions, and the adsorption capacity of MB at $298 \mathrm{~K}$ at different time intervals of 0 to 120 min was determined.

In the isotherm experiments, $0.025 \mathrm{~g}$ SDB-6-K was used to adsorb $25 \mathrm{~mL}$ of each of 100, 500, 1000, 1500, 2000, 2500, 2750, 3000, 3250, and $3500 \mathrm{mg} \mathrm{L}^{-1} \mathrm{MB}$ solutions, and the adsorption performance was carried out for $2 \mathrm{~h}$ at 298,308 , and $318 \mathrm{~K}$. 


\subsection{Adsorption Capacities of Single Dye and Mixed Dyes on SDB-6-K}

To further investigate the adsorption of SDB-6-K, the adsorption capacities of single dye and mixed dyes on SDB-6-K were analyzed. A total of $0.025 \mathrm{~g}$ SDB-6-K was used to adsorb $25 \mathrm{~mL}$ of $1000 \mathrm{mg} \mathrm{L}^{-1} \mathrm{CV}, \mathrm{MO}, \mathrm{RhB}$, and $\mathrm{MB}$ aqueous solutions, and quaternary mixed dyes aqueous solution $\left(\mathrm{CV}+\mathrm{MO}+\mathrm{RhB}+\mathrm{MB}\right.$; each one was $\left.250 \mathrm{mg} \mathrm{L}^{-1}\right)$. Their adsorption performances were conducted for $2 \mathrm{~h}$ at $298 \mathrm{~K}$. The adsorption values were measured at $580 \mathrm{~nm}, 465 \mathrm{~nm}, 554.1 \mathrm{~nm}$, and $664 \mathrm{~nm}$, respectively, which are the maximum adsorption wavelengths of $\mathrm{CV}, \mathrm{MO}, \mathrm{RhB}$, and $\mathrm{MB}$. The adsorption efficiency of commercial activated carbon (AC) for different dyes was used for comparison.

\section{Results and Discussion}

\subsection{Characterization of the As-Prepared Samples}

\subsubsection{Porous Characterization and Element Analysis}

The porous properties of SDBs-K, $\mathrm{SD}$, and $\mathrm{AC}$ were measured by $\mathrm{N}_{2}$ adsorption/desorption isotherm. As the result show in Figure 1a, the raw material (SD) did not exist pores; however, after carbonization and activation, the as-prepared samples (SDBs-K) all exhibited type-I adsorption-desorption isotherms, which indicated the presence of micropores. A type-I adsorption-desorption isotherm is usually used to describe the micropore adsorption and monolayer adsorption, whereas SDB-5-K and SDB-6-K were relatively steep under low pressure, and micropore filling occurred. The linear diagram of the nitrogen isotherm showed pore condensation and $\mathrm{H}_{2}$ type hysteresis, indicating that the pore system was interconnected and shrunk. AC displayed a hysteresis loop at $p / p_{0}>0.5$, which belonged to the type-IV adsorption-desorption isotherm, indicating the existence of micropores and mesopores. From these isotherms, it turned out that SDB-6-K had the highest specific surface area and pore volume compared to other adsorbents. Figure $1 \mathrm{~b}$ shows that the pore characteristics of SDBs-K were mainly micropores, the majority concentrated in the range of $0.6-5.0 \mathrm{~nm}$, and formed by activation of $\mathrm{KOH}$ [25] during high temperature pyrolysis and the $\mathrm{KOH}$ impregnated reaction. The framework of soybean dreg was etched to produce abundant micropores with the interaction between substances and the liberation of gas. In addition, when the activation temperature reached $800^{\circ} \mathrm{C}$, the carbon-reduced potassium metal was vaporized into gaseous potassium, and the potassium vapor entered the internal structure of the carbon and pushed into the interlayer of the carbon, leaving a large number of pores inside, thus forming a large specific surface area and rich pore structure [26].
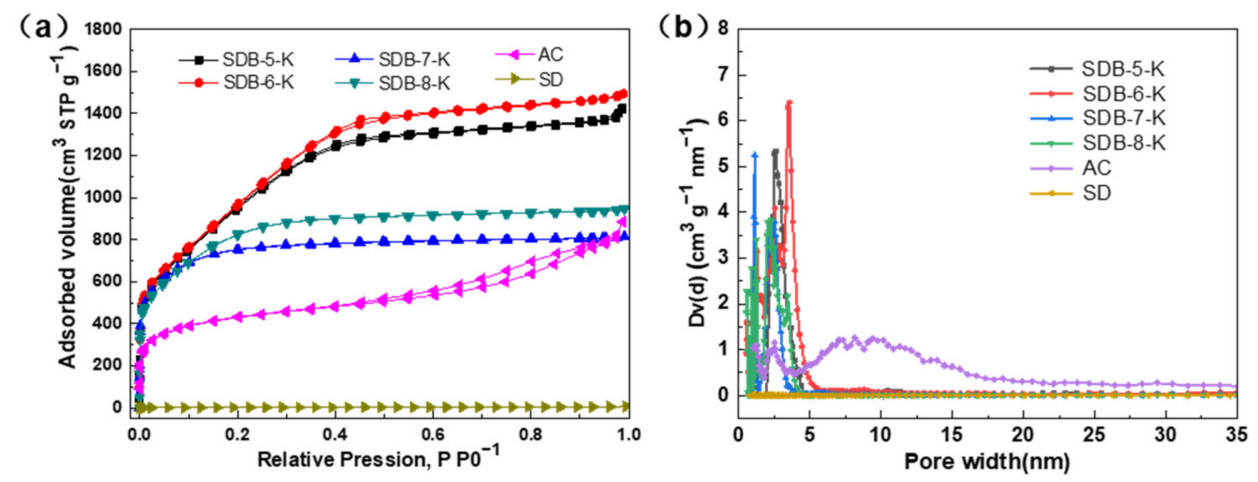

Figure 1. (a) $\mathrm{N}_{2}$ adsorption-desorption isotherms of SDBs-K, AC, and SD; (b) pore diameter distribution of SDBs-K, AC, and SD. AC is activated carbon; SD is soybean dreg.

As the data shown in Table 1 indicates, the SDBs-K prepared at different carbonization temperatures all had high specific surface areas, greater than $2500 \mathrm{~m}^{2} \mathrm{~g}^{-1}$. The surface areas of SDB-5-K, SDB-6-K, SDB-7-K, and SDB-8-K were 2611, 2786, 2604, and $2505 \mathrm{~m}^{2} \mathrm{~g}^{-1}$; the pore volumes were $2.206,2.316,1.465$, and $1.263 \mathrm{~cm}^{3} \mathrm{~g}^{-1}$; and the average pore diameters were $3.378,3.326,2.339$, and $1.941 \mathrm{~nm}$, respectively. From the analysis of data results, the specific surface area, pore volume, and average pore diameter changed with the increase 
of carbonization temperature, which may be because the appropriate temperature would promote the formation of pores, and too high temperature would lead to the destruction of a large number of skeleton carbon and pore structure, so it was determined that SDB-6-K had the best pore structure.

Table 1. Specific surface area, pore volume, and average pore diameter of SDBs-K, AC, and SD.

\begin{tabular}{cccc}
\hline Sample & $\begin{array}{c}\text { Specific Surface } \\
\text { Area }\left(\mathbf{m}^{\mathbf{2}} \mathbf{g}^{-\mathbf{1}} \mathbf{)}\right.\end{array}$ & $\begin{array}{c}\text { Pore Volume } \\
\left(\mathbf{c m}^{\mathbf{3}} \mathbf{g}^{-\mathbf{1}} \mathbf{)}\right.\end{array}$ & $\begin{array}{c}\text { Average Pore } \\
\text { Diameter } \mathbf{( n m})\end{array}$ \\
\hline SDB-5-K & 2611 & 2.206 & 3.378 \\
SDB-6-K & 2786 & 2.316 & 3.326 \\
SDB-7-K & 2604 & 1.465 & 2.339 \\
SDB-8-K & 2505 & 1.263 & 1.941 \\
AC & 1502 & 1.373 & 3.665 \\
SD & 7.130 & 0.011 & 6.110 \\
\hline
\end{tabular}

The element content of SD and SDBs-K as shown in Table 2. After pyrolysis and $\mathrm{KOH}$ activation, the biochar yield of the as-prepared samples was over $11 \%$, among which SDB-6-K reached the highest yield, up to $12.09 \%$. Furthermore, the $\mathrm{C}$ contents of SDBs-K were all over $90 \%$; however, the $\mathrm{O}, \mathrm{H}, \mathrm{N}$, and $\mathrm{S}$ contents were all low, probably due to participation in the formation of gas. Combining the pore structure and biochar yield, SDB-6-K was selected as an optimum bio-adsorbent to remove organic dyes from aqueous solutions.

Table 2. The yield and the elemental analysis of SDBs-K.

\begin{tabular}{ccccccc}
\hline Sample & Yield (\%) & $\mathbf{C ~ ( \% )}$ & O (\%) & H (\%) & N (\%) & S (\%) \\
\hline SDB-5-K & $11.04 \%$ & 91.96 & 6.40 & 1.149 & 0.335 & 0.317 \\
SDB-6-K & $12.09 \%$ & 91.80 & 7.26 & 1.072 & 0.371 & 0.424 \\
SDB-7-K & $12.03 \%$ & 91.14 & 7.58 & 0.842 & 0.351 & 0.272 \\
SDB-8-K & $11.89 \%$ & 90.44 & 8.56 & 0.688 & 0.317 & 0.227 \\
\hline
\end{tabular}

EDS analysis in Figure 2 revealed that the SDB-6-K was composed of carbon (85.03\%), oxygen $(8.42 \%)$, nitrogen $(6.48 \%)$, and sulfur $(0.07 \%)$, which was consistent with the element analysis results, and the main components elements were $\mathrm{C}$ and $\mathrm{O}$; no potassium was detected.

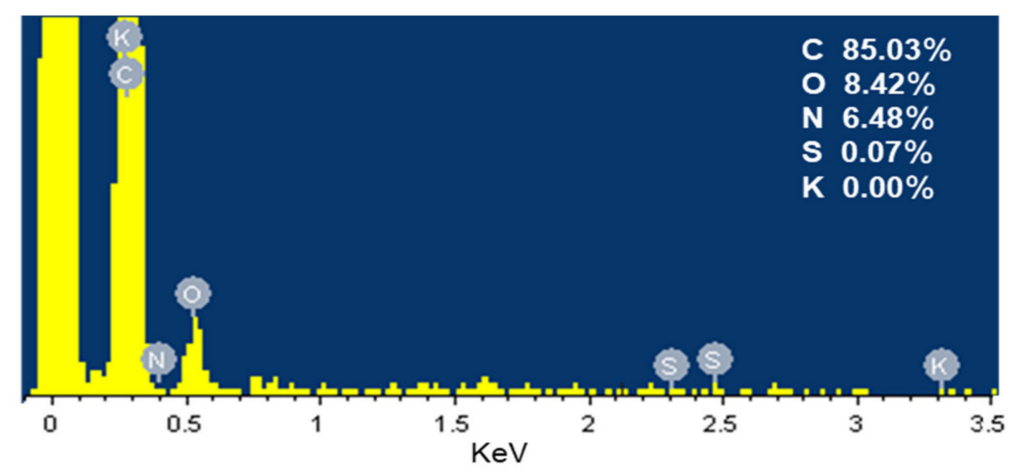

Figure 2. EDS spectrum of SDB-6-K.

\subsubsection{Microstructure and Morphology Analysis}

According to the morphology of SD, SDB-6, SDB-6-K, and AC in Figure 3, the surface structure of SD was smooth, dense, and orderly and composed of many large blocks with few obvious pore structures [27]. After carbonization, abundant folds appeared on the surface of the SDB-6, and the pore structure was almost invisible. However, after $\mathrm{KOH}$ activation, the SDB-6-K possessed a honeycomb structure, with micropores uniformly 
arranged. Compared with SDB-6-K, the AC exhibited a dense and rough surface with different sizes of pores arranged.
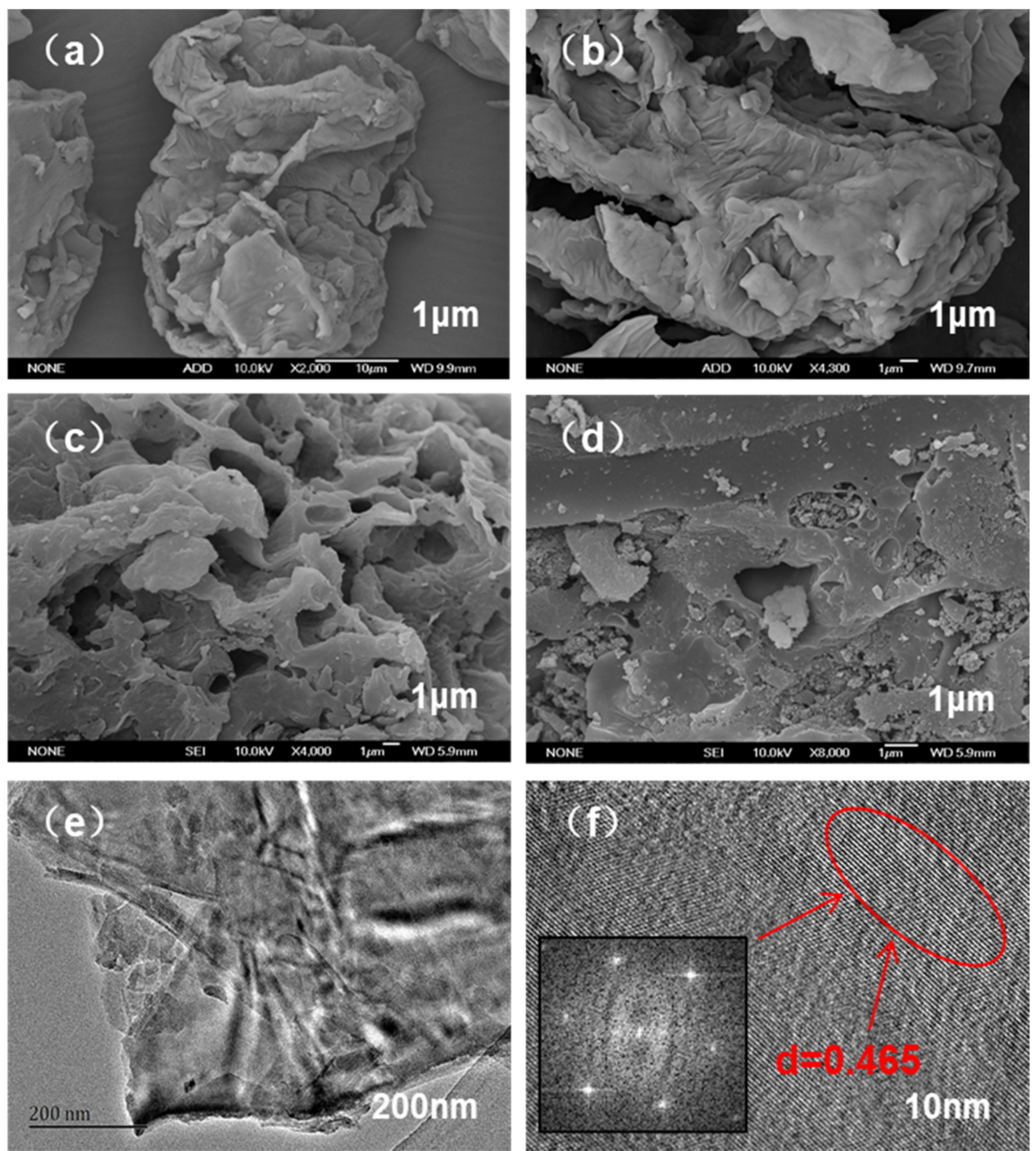

Figure 3. SEM images of (a) SD, (b) SDB-6, (c) SDB-6-K, and (d) AC; (e) TEM image of SDB-6-K; (f) HRTEM image of SDB-6-K.

Furthermore, the TEM images showed the internal apparent structure of SDB-6$\mathrm{K}$ as a layered $\mathrm{C}$ structure of disordered stacks, and the lattice fringe was calculated from the fast Fourier transformation (FFT) of high resolution TEM (HRTEM) to confirm that the upper surface layer was a disordered $C$ with a partial graphite domain, and the distinct lattice fringes with a distance of $0.465 \mathrm{~nm}$, different from the graphite (002) plane $(\mathrm{d}=0.34 \mathrm{~nm})$ [28]. The graphene-like microcrystalline structure may be due to the high-temperature activation of $\mathrm{KOH}$; the original closed hole was opened and reacted with disordered carbon atoms and heteroatoms to open the blocked hole and expose the microcrystalline surface.

\subsubsection{The Phase Composition and Crystal Structure Analysis}

The crystalline structures of SD and SDB-6-K were observed by XRD diffraction peaks. As shown in Figure $4 a$, a strong diffraction peak at $2 \theta=20.7^{\circ}$ appeared in the spectra of SD, corresponding to (002) crystal planes of cellulose [29]. After high temperature pyrolysis and $\mathrm{KOH}$ activation, there were two broad peaks at $2 \theta=26.5^{\circ}$ and $43.3^{\circ}$, which appeared in the spectra of SDB-6-K and corresponded to the (002) and (101) diffraction peaks, respectively, 
suggesting the presence of amorphous carbon [30], which was a crystal with the same structure as graphite; however, the lamellar structure formed by the hexagonal torus of carbon atom was disordered and irregular, with defects in crystal formation and small grains. Moreover, the low-intensity and broadened peaks indicated that the structure of SDB-6-K was highly disordered carbon [31].
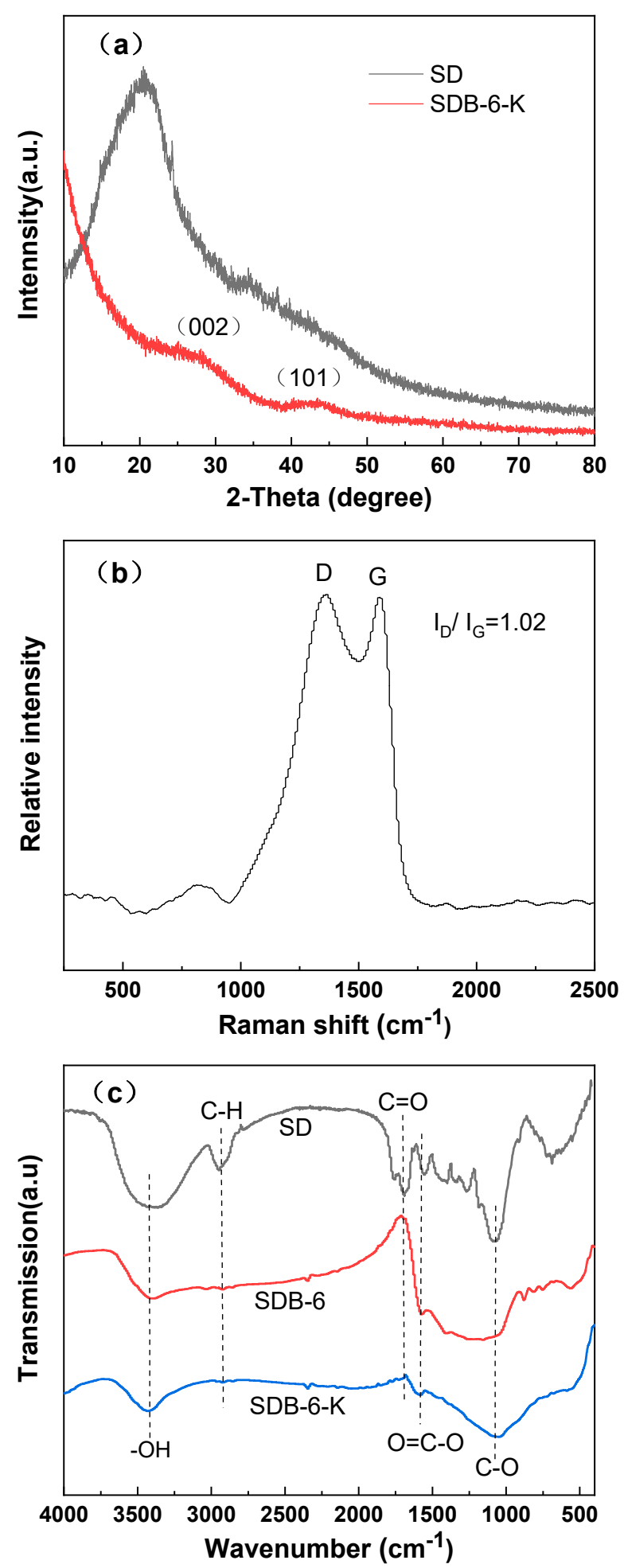

Figure 4. (a) XRD spectra of SD and SDB-6-K; (b) Raman spectra of SDB-6-K; (c) FTIR spectra of SD, SDB-6, and SDB-6-K. 
There were two peaks near $1360 \mathrm{~cm}^{-1}$ and $1590 \mathrm{~cm}^{-1}$ in the Raman spectrum. As seen in Figure $4 \mathrm{~b}$, the D peak $\left(1360 \mathrm{~cm}^{-1}\right)$ was attributed to the disordered sp3-hybridized carbon, indicating the existence of disordered carbon structure, and the $G$ peak $\left(1590 \mathrm{~cm}^{-1}\right)$ was related to the vibration of sp2-hybridized carbon atom in the graphite layer $[32,33]$. The ratio of $\mathrm{I}_{\mathrm{D}} / \mathrm{I}_{\mathrm{G}}$ represents the measurement of the disorder degree of graphite layers and the size of microcrystalline. Here, the $\mathrm{I}_{\mathrm{D}} / \mathrm{I}_{\mathrm{G}}$ ratio of SDB-6-K was 1.002 , indicating that it had a certain graphitization structure, which was consistent with the TEM and XRD results.

The functional group compositions of as-prepared samples were investigated by FTIR, as seen in Figure 4c. As the sample contained an -OH functional group, the FTIR spectrum exhibited a peak at 3300-3500 $\mathrm{cm}^{-1}$ [34]. Due to the presence of a COO-functional group on the sample surface, the characteristic peak appeared at $1540-1650 \mathrm{~cm}^{-1}$ in the SD, SDB-6, and SDB-6-K spectra, and the spectra showed that the $\mathrm{C}-\mathrm{OH}$ stretching vibration peak appeared at $1000-1300 \mathrm{~cm}^{-1}$ [16]. The peak at $2830-2930 \mathrm{~cm}^{-1}$ in the SD spectrum was ascribed to the $\mathrm{C}-\mathrm{H}$ stretching vibration, followed by a peak located at $1680-1750 \mathrm{~cm}^{-1}$ attributed to the $\mathrm{C}=\mathrm{O}$ stretching mode. From analysis of spectrum results, it could be demonstrated that most organic substrates had been removed by pyrolysis, and the asprepared sample contained abundant functional groups, which greatly promoted the adsorption of organic dyes.

As can be observed from XPS images in Figure 5a, there were C1s $(286.1 \mathrm{eV})$ and O1s $(536.2 \mathrm{eV})$ peaks in the full X-ray photoelectron spectrum of SDB-6-K, containing a large amount of carbon $(91.08 \%)$ and a small amount of oxygen elements $(8.92 \%)$, which was consistent with the element content analysis results of EA. As shown in Figure $5 b$, the deconvolution of the $\mathrm{C} 1 \mathrm{~s}$ peak produced three individual peaks, representing $\mathrm{C}-\mathrm{O}$, carboxyl (COO-) and carbonyl $(\mathrm{C}=\mathrm{O})$ groups, respectively [33]. The surface of SDB6-K had rich active oxygen-containing functional groups, and the exposure of defects provided a wealth of active sites; this result was consistent with that observed by FTIR spectroscopy [35].
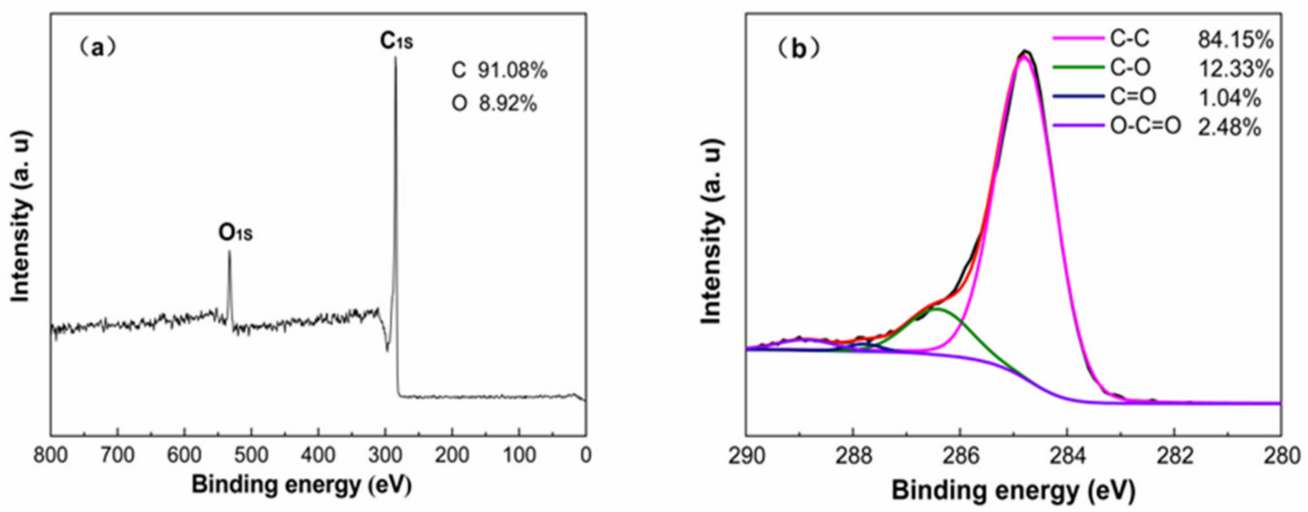

Figure 5. (a) XPS survey; (b) high-resolution spectra of C1s for SDB-6-K.

\subsection{Study of Adsorption Performance of Organic Dyes}

\subsubsection{Adsorption Kinetics Study}

Adsorption kinetics is critical to analyze adsorption mechanism. In order to elucidate the adsorption behavior of SDB-6-K on MB, two kinetic models were applied to analyze the adsorption mechanism: pseudo-first-order [36], and pseudo-second-order [37]. The formula is as follows:

$$
\begin{gathered}
\ln \left(\mathrm{q}_{\mathrm{e}}-\mathrm{q}_{\mathrm{t}}\right)=\ln \mathrm{q}_{\mathrm{e}}-\mathrm{k}_{1} \mathrm{t} \\
\frac{\mathrm{t}}{\mathrm{q}_{\mathrm{t}}}=\frac{1}{\mathrm{k}_{2} \mathrm{q}_{\mathrm{e}}{ }^{2}}+\frac{\mathrm{t}}{\mathrm{q}_{\mathrm{e}}}
\end{gathered}
$$


where $\mathrm{q}_{\mathrm{e}}\left(\mathrm{mg} \mathrm{g}^{-1}\right)$ is the adsorption amount of dye at equilibrium and $\mathrm{q}_{\mathrm{t}}\left(\mathrm{mg} \mathrm{g}^{-1}\right)$ is the adsorption amount of dye at time $\mathrm{t}(\mathrm{min}) ; \mathrm{k}_{1}\left(\mathrm{~min}^{-1}\right)$ and $\mathrm{k}_{2}\left(\mathrm{~g} \mathrm{mg}^{-1} \mathrm{~min}^{-1}\right)$ are the rate constants from the two kinetic models, respectively.

Figure 6a indicated the adsorption capacity of SDB-6-K to different concentrations of $\mathrm{MB}$ at different adsorption times. With the extension of adsorption time, the adsorption efficiency increased until the adsorption equilibrium was reached. Furthermore, the maximum absorption amounts $\mathrm{Q}\left(\mathrm{mg} \mathrm{g}^{-1}\right)$ of 1000,2000 , and $3000 \mathrm{mg} \mathrm{L}^{-1} \mathrm{MB}$ were 999.7, 1982 , and $2538 \mathrm{mg} \mathrm{g}^{-1}$, and removal efficiencies $\mathrm{R}(\%)$ were $99.97 \%, 99.10 \%$, and $84.60 \%$, respectively. The adsorption efficiency of SDB-6-K on MB increased rapidly within $0.5 \mathrm{~h}$ and reached the adsorption equilibrium within $30 \mathrm{~min}$, which may have been caused by the existence of effective binding sites and abundant microporous structures on the surface of SDB-6-K. With adsorption time extension, the adsorption process reached balance, and the adsorption sites reached saturation, so the adsorption capacity was maintained in equilibrium.

Figure $6 \mathrm{~b}, \mathrm{c}$ displays the MB experimental data and the fitting of the two kinetics models, and the two kinetics model fitting results of SDB-6-K adsorption of MB are summarized in Table 3. The results showed that the pseudo-second-order model had significantly higher $\mathrm{R}^{2}$ (coefficient of determination) values $(>0.9999)$ in the three concentrations of MB than the pseudo-first-order model, suggesting that the adsorption of MB on SDB-6-K was also related to chemical action. Thus, the pseudo-second-order model was the optimum model to explain the adsorption of MB using SDB-6-K, being used to calculate the adsorption amounts at equilibrium of 1000, 2000, and $3000 \mathrm{mg} \mathrm{L}^{-1} \mathrm{MB}$ on SDB-6-K, which were 1000,1985 , and $2540 \mathrm{mg} \mathrm{g}^{-1}$, respectively, in good consistency with experimental data (999.7, 1982, and $2538 \mathrm{mg} \mathrm{g}^{-1}$ ), which indicated an effective adsorption of MB by SDB-6-K. This may be attributed to the high surface area and abundant functional groups, which promoted the rapid diffusion of organic dye molecules.

Table 3. Kinetic model parameters for the adsorption of MB onto SDB-6-K at different dye concentrations.

\begin{tabular}{|c|c|c|c|c|c|c|c|c|}
\hline \multirow[b]{2}{*}{ Sample } & \multirow[b]{2}{*}{$\mathrm{C}_{0}\left(\mathrm{mg} \mathrm{L}^{-1}\right)$} & \multirow[b]{2}{*}{$\begin{array}{l}\mathrm{q}_{\mathrm{e}}, \text { Experiment } \\
\left(\mathrm{mg} \mathrm{g}^{-1}\right)\end{array}$} & \multicolumn{3}{|c|}{ Pseudo-First-Order } & \multicolumn{3}{|c|}{ Pseudo-Second-Order } \\
\hline & & & $\begin{array}{c}\mathrm{q}_{\mathrm{e}} \\
\text { Calculated } \\
\left(\mathrm{mg} \mathrm{g}^{-1}\right)\end{array}$ & $\begin{array}{c}\mathrm{k}_{1} \\
\left(\min ^{-1}\right)\end{array}$ & $\mathbf{R}^{2}$ & $\begin{array}{c}\mathrm{q}_{\mathrm{e}} \\
\text { Calculated } \\
\left(\mathrm{mg} \mathrm{g}^{-1}\right)\end{array}$ & $\frac{\mathrm{k}_{2}}{\left(\mathrm{~g} \mathrm{mg}^{-1} \min ^{-1}\right)}$ & $\mathbf{R}^{2}$ \\
\hline \multirow{3}{*}{ SBD-6-K } & 1000 & 999.7 & 0.158 & 0.0430 & 0.9563 & 1000 & 0.9820 & 1.00 \\
\hline & 2000 & 1982 & 79.17 & 0.0537 & 0.8837 & 1985 & 0.0028 & 1.00 \\
\hline & 3000 & 2538 & 65.91 & 0.0361 & 0.7103 & 2540 & 0.0014 & 1.00 \\
\hline
\end{tabular}

\subsubsection{Adsorption Isotherms Study}

In order to explain the adsorption mechanism of SDB-6-K, Langmuir [38] and Freundlich [39] isotherm models were employed to fit the adsorption isotherm data.

The Langmuir isotherm model assumes that monolayer adsorption occurs on the limited active sites on the surface of the adsorbent, the adsorption capacity between the adsorption sites is the same, and there is no interaction between the adsorbed molecules. The Langmuir equation can be expressed as

$$
\frac{C_{e}}{q_{e}}=\frac{C_{e}}{q_{m}}+\frac{1}{k_{L} q_{m}}
$$



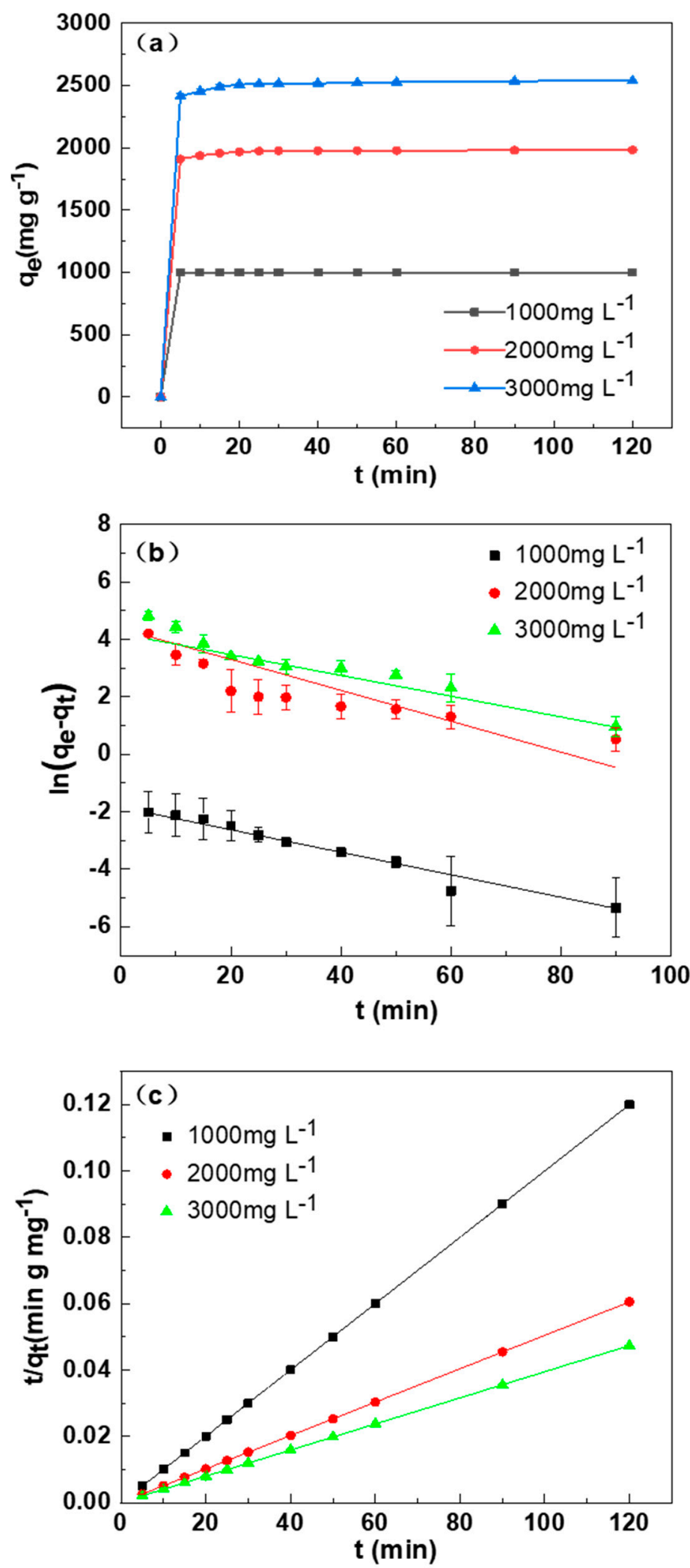

Figure 6. (a) Effect of the contact time on methylene blue (MB) adsorption by SDB-6-K. (b) The pseudo-first-order and (c) pseudo-second-order for the MB adsorption by SDB-6-K. Conditions: $\mathrm{T}=298 \mathrm{~K} ; \mathrm{m}=0.025 \mathrm{~g} ; \mathrm{V}=25 \mathrm{~mL} ; \mathrm{C}_{0}=1000,2000,3000 \mathrm{mg} \mathrm{L}^{-1}$. 
The Freundlich isotherm model assumes multilayer adsorption due to uneven adsorption heat distributed on the uneven surface of the adsorption material. The Freundlich equation can be expressed as

$$
\ln \mathrm{q}_{\mathrm{e}}=\ln \mathrm{k}_{\mathrm{F}}+\frac{1}{\mathrm{n}_{\mathrm{F}}} \ln \mathrm{C}_{\mathrm{e}}
$$

where $\mathrm{C}_{\mathrm{e}}\left(\mathrm{mg} \mathrm{g}^{-1}\right)$ and $\mathrm{q}_{\mathrm{e}}\left(\mathrm{mg} \mathrm{g}^{-1}\right)$ are the concentrations of dye in solution and in adsorbent at the adsorption equilibrium, respectively. $\mathrm{q}_{\mathrm{m}}\left(\mathrm{mg} \mathrm{g}^{-1}\right)$ is the maximum adsorption capacity of dye, $\mathrm{k}_{\mathrm{L}}\left(\mathrm{L} \mathrm{mg}^{-1}\right)$ is the Langmuir isotherm constant, and $\mathrm{k}_{\mathrm{F}}\left(\mathrm{mg} \mathrm{g}^{-1}\right)$ is the Freundlich isotherm constant.

The adsorption isotherm of SDB-6-K for MB at different initial concentrations of MB and temperatures are illustrated in Figure 7a. It could be observed that the saturation adsorption capacity first increased sharply and then kept constant with the rising of the initial concentration of MB. Moreover, the temperature had no significant effect on the adsorption capacity when the initial concentration of MB was lower $\left(2000 \mathrm{mg} \mathrm{L}^{-1}\right)$, while the higher the temperature, the greater the adsorption capacity when the initial concentration of MB was more than $2000 \mathrm{mg} \mathrm{L}^{-1}$, which was indicating that the physical adsorption was dominant at lower initial concentration of $\mathrm{MB}$, and the chemical adsorption was the main fashion at higher concentration.

Figure $7 \mathrm{~b}, \mathrm{c}$ indicates the fitting of experimental data with the two isotherm models, and the parameters and correlation coefficients of the two models are observed in Table 4. There were higher $\mathrm{R}^{2}$ values $(0.9994,0.9999$, and 1.00$)$ at $298 \mathrm{~K}, 308 \mathrm{~K}$, and $318 \mathrm{~K}$, respectively, in the Langmuir isotherm model, compared with those in the Freundlich isotherm model, and thus the Freundlich equation was more suitable for describing the adsorption of MB on SDB-6-K, indicating that this adsorption process was single-layer adsorption.

Table 4. Isotherm model parameters for the adsorption of MB onto SDB-6-K at different temperatures.

\begin{tabular}{lccccccc}
\hline \multirow{2}{*}{ Sample } & \multirow{2}{*}{$\mathbf{T} \mathbf{K}$} & \multicolumn{3}{c}{ Langmuir } & \multicolumn{3}{c}{ Freundlich } \\
\cline { 3 - 8 } & & $\mathbf{q}_{\mathbf{m}} \mathbf{( \mathbf { m g ~ g } ^ { - \mathbf { 1 } } )}$ & $\mathbf{K}_{\mathbf{L}} \mathbf{( \mathbf { L ~ } ~ \mathbf { ~ g } ^ { - \mathbf { 1 } } )}$ & $\mathbf{R}^{\mathbf{2}}$ & $\mathbf{n}_{\mathbf{F}}$ & $\mathbf{K}_{\mathbf{F}}$ & $\mathbf{R}^{\mathbf{2}}$ \\
\hline \multirow{3}{*}{ SDB-6-K } & 298 & 2488 & 0.39 & 0.9994 & 16.95 & 1746 & 0.8493 \\
& 308 & 2595 & 0.37 & 0.9999 & 13.67 & 1678 & 0.8866 \\
& 318 & 2639 & 1.04 & 1.00 & 11.65 & 1672 & 0.9121 \\
\hline
\end{tabular}

\subsubsection{Adsorption Thermodynamics Study}

For the purpose of interpreting the thermodynamic behavior of $\mathrm{MB}$ adsorption for SDB-6-K, thermodynamic parameters were calculated using the following standard thermodynamic equations [40]:

$$
\begin{gathered}
\ln \mathrm{K}_{\mathrm{c}}=\frac{-\Delta \mathrm{H}}{\mathrm{RT}}+\frac{\Delta \mathrm{S}}{\mathrm{R}} \\
\Delta \mathrm{G}=-\mathrm{RT}_{\ln \mathrm{K}_{\mathrm{C}}} \\
\mathrm{K}_{\mathrm{C}}=\frac{\mathrm{q}_{\mathrm{e}}}{\mathrm{C}_{\mathrm{e}}}
\end{gathered}
$$

where $\mathrm{K}_{\mathrm{c}}$ is the equilibrium constant, $\Delta \mathrm{H}\left(\mathrm{kJ} \mathrm{mol}^{-1}\right)$ is the enthalpy change, $\Delta \mathrm{S}\left(\mathrm{J} \mathrm{K}^{-1} \mathrm{~mol}^{-1}\right)$ is the entropy change, $\Delta \mathrm{G}\left(\mathrm{kJ} \mathrm{mol}^{-1}\right)$ is the free energy change, $\mathrm{R}\left(8.314 \mathrm{~J} \mathrm{~K}^{-1} \mathrm{~mol}^{-1}\right)$ is the universal gas constant, and $\mathrm{T}(\mathrm{K})$ is the system temperature. 

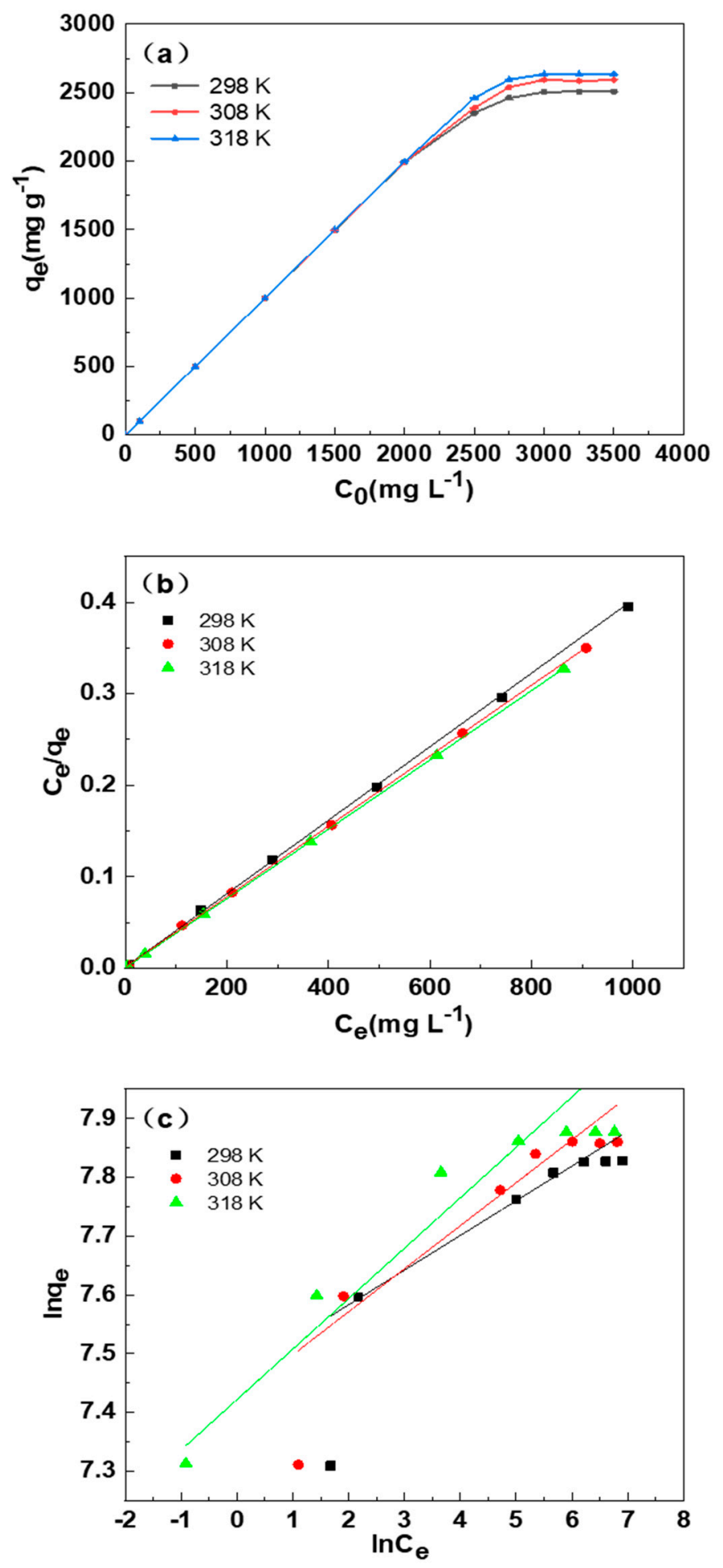

Figure 7. (a) Effect of dye initial concentration and temperature on the adsorption performance. (b) The Langmuir isotherms and (c) Freundlich isotherms for the MB adsorption by SDB-6-K. Conditions: $\mathrm{T}=298,308,318 \mathrm{~K} ; \mathrm{m}=0.025 \mathrm{~g} ; \mathrm{V}=25 \mathrm{~mL} ; \mathrm{C}_{0}=3000 \mathrm{mg} \mathrm{L}^{-1}$.

Table 5 provides the thermodynamic parameters. The values of $\Delta \mathrm{H}$ and $\Delta \mathrm{S}$ can be obtained by calculating the slope and the intercept of the linear plot of $\ln \mathrm{Kc}$ and $1 / \mathrm{T}$. Both $\Delta \mathrm{H}$ and $\Delta \mathrm{S}$ were positive values, indicating that the adsorption reaction was endothermic, and the randomness of the solid-liquid interface during the adsorption process increased [41]. In addition, the $\Delta \mathrm{H}$ values of the SDB-6-K were greater than zero, 
indicating that $\mathrm{MB}$ adsorption onto the SDB-6-K was an endothermic reaction. The $\Delta \mathrm{G}$ values were negative, indicating that the MB adsorption on SDB-6-K was spontaneous adsorption, and it became more favorable at high adsorption temperatures. The positive $\Delta \mathrm{S}$ confirmed the considerable interactions between the SDB-6-K functional sites and MB molecules.

Table 5. Thermodynamic parameters for the adsorption of MB onto SDB-6-K at different temperatures.

\begin{tabular}{|c|c|c|c|}
\hline $\mathrm{T}$ & $\Delta \mathrm{G}\left(\mathrm{kJ} \mathrm{mol}^{-1}\right)$ & $\Delta \mathrm{H}\left(\mathrm{kJ} \mathrm{mol}^{-1}\right)$ & $\Delta S\left(\mathrm{~J} \mathrm{~K}^{-1} \mathrm{~mol}^{-1}\right)$ \\
\hline 298 & -4.0314 & & \\
\hline 308 & -4.6963 & 15.7828 & 66.4906 \\
\hline 318 & -5.3612 & & \\
\hline
\end{tabular}

In sum, the as-prepared sample (SDB-6-K) derived from soybean dreg has superior removal performance for organic dyes, which may be attributed to its abundant porous structure and high specific surface area. The high adsorption capacity of SDB-6-K may also be due to the abundant functional groups on its surface.

\subsubsection{Adsorption Performances of Single Dye and Mixed Dyes on SDB-6-K}

Considering the practical applications of the adsorbent, the adsorption performances for different single dyes and mixed dyes on SDB-6-K were investigated, and commercial activated carbon (AC) was used for comparison. As illustrated in Figure 8a, SDB-6-K had high adsorption efficiencies for four single dyes, and the adsorption amounts $\mathrm{Q}\left(\mathrm{mg} \mathrm{g}^{-1}\right)$ of CV, MO, RhB, and MB were 995.15, 977.52, 999.71, and $999.66 \mathrm{mg} \mathrm{g}^{-1}$, respectively, and the removal efficiency $\mathrm{R}(\%)$ was $99.52,97.75,99.97$, and $99.97 \%$, respectively. Compared with a single dye, SDB-6-K also had higher adsorption capacity for mixed dyes, as illustrated in Figure $8 \mathrm{~b}$, and the adsorption amounts $\mathrm{Q}\left(\mathrm{mg} \mathrm{g}^{-1}\right)$ of $\mathrm{CV}, \mathrm{MO}, \mathrm{RhB}$, and $\mathrm{MB}$ were $249.23,249.93,249.77$, and $249.73 \mathrm{mg} \mathrm{g}^{-1}$, and the removal efficiency $\mathrm{R}(\%)$ was $99.69,99.97$, 99.91, and $99.89 \%$, respectively. It could be demonstrated that SDB-6-K exhibited higher adsorption efficiency for different single dyes and mixed dyes than $\mathrm{AC}$, and has enormous potential in the application of dye wastewater treatment. In addition, compared with the maximum adsorption capacities of $\mathrm{MB}$ using the adsorbents derived from different sources previously reported, as shown in Table 6, it could be seen that the as-prepared SDB-6-K exhibited better adsorption performance of $\mathrm{MB}$ compared with the other adsorbents, owing to its graphene-like structure, large specific surface area, and developed porosity.

Table 6. Comparation of the maximum MB adsorption capacities of adsorbents prepared from different sources.

\begin{tabular}{ccccc}
\hline Adsorbent & BET $\left(\mathbf{m}^{\mathbf{2}} \mathbf{g}^{-\mathbf{1}}\right)$ & $\mathbf{q}_{\max }\left(\mathbf{m g} \mathbf{g}^{-\mathbf{1}}\right)$ & $\mathbf{q}_{\mathbf{m a x}} / \mathbf{B E T}\left(\mathbf{m g ~ m}^{-\mathbf{2}}\right)$ & Reference \\
\hline Banana peel & 2086 & 385.12 & 0.185 & {$[42]$} \\
Bean dreg & 1738.95 & 434.78 & 0.250 & {$[43]$} \\
Seaweed & 926.39 & 512.67 & 0.553 & {$[44]$} \\
Coffee grounds & 1910 & 653.6 & 0.342 & {$[11]$} \\
Coconut shells & 876.14 & 200 & 0.228 & {$[45]$} \\
Bamboo & 1896 & 454.20 & 0.240 & {$[46]$} \\
Rattan & 1135 & 359 & 0.316 & {$[47]$} \\
Fish scales & 1867.67 & 184.40 & 0.099 & {$[48]$} \\
Soybean dreg & 2786 & 2636 & 0.946 & This study \\
\hline
\end{tabular}



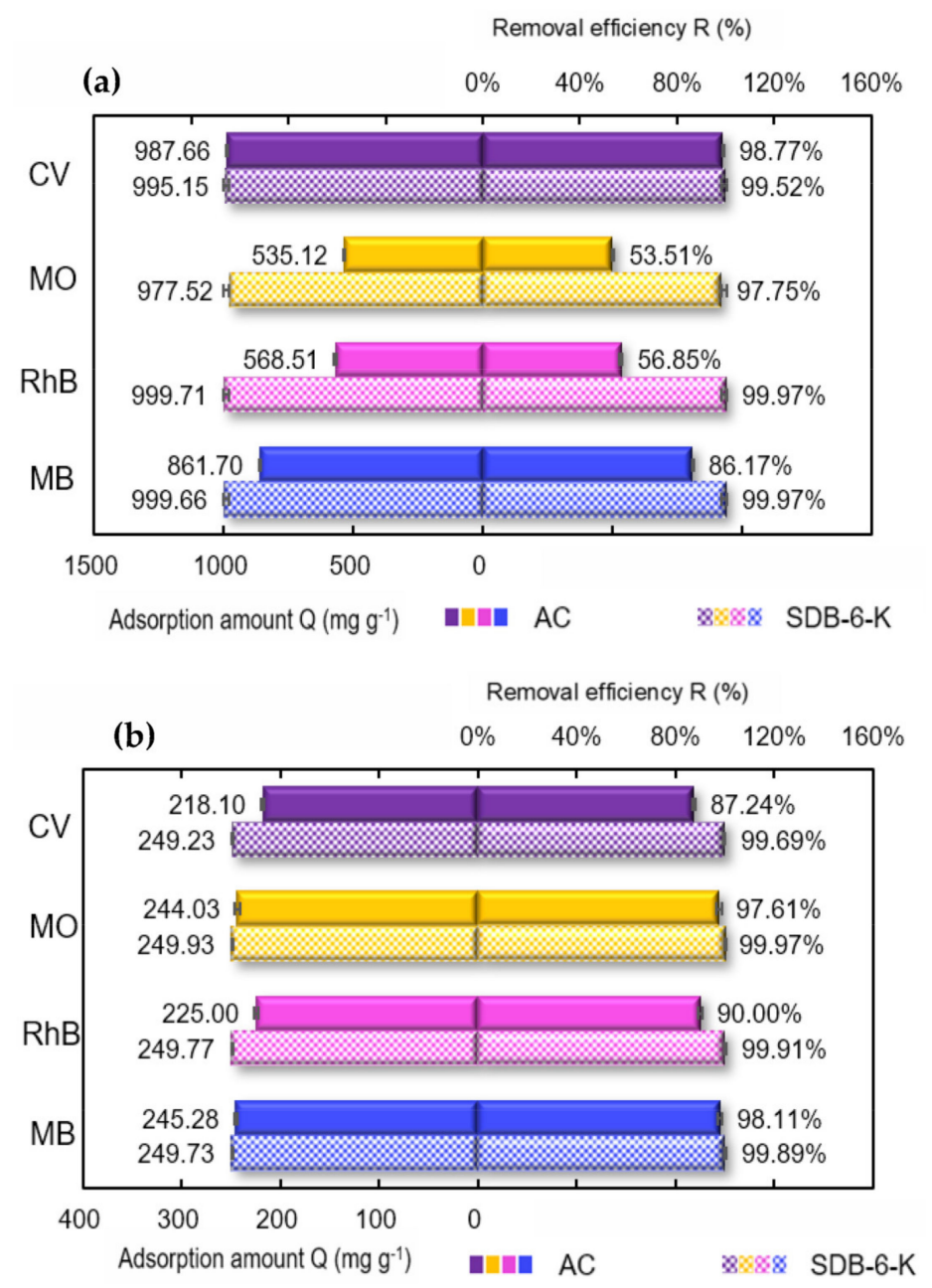

Figure 8. (a) Adsorption of different single dyes by SDB-6-K and AC; (b) adsorption of mixture dyes by SDB-6-K and AC. Conditions: (a) $1000 \mathrm{mg} \mathrm{L}^{-1} \mathrm{CV} / \mathrm{MO} / \mathrm{RhB} / \mathrm{MB}$; (b) $\mathrm{MB}+\mathrm{RhB}+\mathrm{MO}+\mathrm{CV}$, each is $250 \mathrm{mg} \mathrm{L}{ }^{-1} ; \mathrm{T}=298 \mathrm{~K} ; \mathrm{m}=0.025 \mathrm{~g} ; \mathrm{V}=25 \mathrm{~mL} ; \mathrm{t}=2 \mathrm{~h}$. SDB-6-K and AC. Conditions: (a) $1000 \mathrm{mg} \mathrm{L}^{-1}$ $\mathrm{CV} / \mathrm{MO} / \mathrm{RhB} / \mathrm{MB} ;(\mathbf{b}) \mathrm{MB}+\mathrm{RhB}+\mathrm{MO}+\mathrm{CV}$, each is $250 \mathrm{mg} \mathrm{L}^{-1} ; \mathrm{T}=298 \mathrm{~K} ; \mathrm{m}=0.025 \mathrm{~g} ; \mathrm{V}=25 \mathrm{~mL}$; $\mathrm{t}=2 \mathrm{~h}$.

\section{Conclusions}

The porous carbon prepared by the two-step method (high temperature pyrolysis and $\mathrm{KOH}$ activation method) using soybean dreg as a raw material had a high specific surface area, a developed porosity, and suitable pore diameter and pore volume. The maximum adsorption amount of SDB-6-K to MB reached $2636 \mathrm{mg} \cdot \mathrm{g}^{-1}$ at $318 \mathrm{~K}$. It had excellent adsorption capacity for different single dyes $(\mathrm{CV}, \mathrm{MO}, \mathrm{RhB}, \mathrm{MB})$ and mixed dyes $(\mathrm{CV}+\mathrm{MO}+\mathrm{RhB}+\mathrm{MB})$. In general, SDB-6-K has good adsorption capacity, which has good practical application potential in the field of dye wastewater treatment in the future.

Author Contributions: Designed the study, performed the experiments and writing —original draft preparation: Z.Y.; performed the experiments and methodology: L.H.; writing-review and editing, analyzed the data: H.L. and L.J.; supervision funding acquisition and project administration: X.L.; software and methodology: C.Z.; formal analysis and investigation: J.Z. and G.Y. All authors have read and agreed to the published version of the manuscript.

Funding: This research was funded by the National Key Research and Development Program of China, grant number 2016YFD0400401.

Institutional Review Board Statement: Not applicable.

Informed Consent Statement: Not applicable. 
Data Availability Statement: Data sharing is not applicable to this article.

Conflicts of Interest: The authors declare no conflict of interest.

\section{References}

1. Haque, E.; Lee, J.E.; Jang, I.T.; Hwang, Y.K.; Chang, J.S.; Jegal, J.; Jhung, S.H. Adsorptive removal of methyl orange from aqueous solution with metal-organic frameworks, porous chromium-benzenedicarboxylates. J. Hazard. Mater. 2010, 181, 535-542. [CrossRef] [PubMed]

2. Verma, A.K.; Dash, R.R.; Bhunia, P. A review on chemical coagulation/flocculation technologies for removal of colour from textile wastewaters. J. Environ. Manag. 2012, 93, 154-168. [CrossRef]

3. Wang, C.; Jiang, X.; Zhou, L.; Xia, G.; Chen, Z.; Duan, M.; Jiang, X. The preparation of organo-bentonite by a new gemini and its monomer surfactants and the application in MO removal: A comparative study. Chem. Eng. J. 2013, 219, 469-477. [CrossRef]

4. Hosseini, S.; Khan, M.A.; Malekbala, M.R.; Cheah, W.; Choong, T.S.Y. Carbon coated monolith, a mesoporous material for the removal of methyl orange from aqueous phase: Adsorption and desorption studies. Chem. Eng. J. 2011, 171, 1124-1131. [CrossRef]

5. Shen, Y.; Fang, Q.; Chen, B. Environmental applications of three-dimensional graphene-based macrostructures: Adsorption, transformation, and detection. Environ. Sci. Technol. 2015, 49, 67-84. [CrossRef] [PubMed]

6. He, C.; Hu, X. Anionic Dye Adsorption on Chemically Modified Ordered Mesoporous Carbons. Ind. Eng. Chem. Res. 2011, 50, 14070-14083. [CrossRef]

7. Xu, P.; Zeng, G.M.; Huang, D.L.; Feng, C.L.; Hu, S.; Zhao, M.H.; Lai, C.; Wei, Z.; Huang, C.; Xie, G.X.; et al. Use of iron oxide nanomaterials in wastewater treatment: A review. Sci. Total Environ. 2012, 424, 1-10. [CrossRef]

8. Sinha, A.K.; Pradhan, M.; Sarkar, S.; Pal, T. Large-scale solid-state synthesis of $\mathrm{Sn}-\mathrm{SnO}_{2}$ nanoparticles from layered SnO by sunlight: A material for dye degradation in water by photocatalytic reaction. Environ. Sci. Technol. 2013, 47, 2339-2345. [CrossRef]

9. Keyhanian, F.; Shariati, S.; Faraji, M.; Hesabi, M. Magnetite nanoparticles with surface modification for removal of methyl violet from aqueous solutions. Arab. J. Chem. 2016, 9, S348-S354. [CrossRef]

10. Yagub, M.T.; Sen, T.K.; Afroze, S.; Ang, H.M. Dye and its removal from aqueous solution by adsorption: A review. Adv. Colloid Interface 2014, 209, 172-184. [CrossRef]

11. Wen, X.; Liu, H.; Zhang, L.; Zhang, J.; Fu, C.; Shi, X.; Chen, X.; Mijowska, E.; Chen, M.J.; Wang, D.Y. Large-scale converting waste coffee grounds into functional carbon materials as high-efficient adsorbent for organic dyes. Bioresour. Technol. 2019, 272, 92-98. [CrossRef] [PubMed]

12. Wong, S.; Ngadi, N.; Inuwa, I.M.; Hassan, O. Recent advances in applications of activated carbon from biowaste for wastewater treatment: A short review. J. Clean. Prod. 2018, 175, 361-375. [CrossRef]

13. Saroyan, H.S.; Giannakoudakis, D.A.; Sarafidis, C.S.; Lazaridis, N.K.; Deliyanni, E.A. Effective impregnation for the preparation of magnetic mesoporous carbon: Application to dye adsorption. J. Chem. Technol. Biotechnol. 2017, 92, 1899-1911. [CrossRef]

14. Kang, D.; Yu, X.; Ge, M.; Xiao, F.; Xu, H. Novel Al-doped carbon nanotubes with adsorption and coagulation promotion for organic pollutant removal. J. Environ. Sci. 2017, 54,1-12. [CrossRef] [PubMed]

15. Banerjee, S.; Chattopadhyaya, M.C. Adsorption characteristics for the removal of a toxic dye, tartrazine from aqueous solutions by a low cost agricultural by-product. Arab. J. Chem. 2017, 10, S1629-S1638. [CrossRef]

16. Yu, Y.; Qiao, N.; Wang, D.; Zhu, Q.; Fu, F.; Cao, R.; Wang, R.; Liu, W.; Xu, B. Fluffy honeycomb-like activated carbon from popcorn with high surface area and well-developed porosity for ultra-high efficiency adsorption of organic dyes. Bioresour. Technol. 2019, 285, 121340. [CrossRef]

17. Astuti, W.; Sulistyaningsih, T.; Kusumastuti, E.; Thomas, G.; Kusnadi, R.Y. Thermal conversion of pineapple crown leaf waste to magnetized activated carbon for dye removal. Bioresour. Technol. 2019, 287, 121426. [CrossRef] [PubMed]

18. Sulak, M.T.; Demirbas, E.; Kobya, M. Removal of Astrazon Yellow 7GL from aqueous solutions by adsorption onto wheat bran. Bioresour. Technol. 2007, 98, 2590-2598. [CrossRef]

19. Sewu, D.D.; Jung, H.; Kim, S.S.; Lee, D.S.; Woo, S.H. Decolorization of cationic and anionic dye-laden wastewater by steamactivated biochar produced at an industrial-scale from spent mushroom substrate. Bioresour. Technol. 2019, 277, 77-86. [CrossRef]

20. Arami, M.; Limaee, N.Y.; Mahmoodi, N.M.; Tabrizi, N.S. Removal of dyes from colored textile wastewater by orange peel adsorbent: Equilibrium and kinetic studies. J. Colloid Interface Sci. 2005, 288, 371-376. [CrossRef]

21. Jiang, L.; Guo, X.Y.; Wei, D.H. The Analysis of Comparative Advantages of Main Soybean Producing Countries. Adv. Mater. Res. 2011, 271-273, 872-876. [CrossRef]

22. Mo, W.Y.; Man, Y.B.; Wong, M.H. Use of food waste, fish waste and food processing waste for China's aquaculture industry: Needs and challenge. Sci. Total Environ. 2018, 613-614, 635-643. [CrossRef] [PubMed]

23. Wachiraphansakul, S.; Devahastin, S. Drying Kinetics and Quality of Soy Residue (Okara) Dried in a Jet Spouted-Bed Dryer. Dry. Technol. 2005, 23, 1229-1242. [CrossRef]

24. Taruna, I.; Jindal, V.K. Drying of Soy Pulp (Okara) in a Bed of Inert Particles. Dry. Technol. 2006, 20, 1035-1051. [CrossRef]

25. Wang, H.; Gao, Q.; Hu, A.J. High Hydrogen Storage Capacity of Porous Carbons Prepared. J. Am. Chem. Soc. 2009, 131, 7016-7022. [CrossRef]

26. Wang, J.; Kaskel, S. KOH activation of carbon-based materials for energy storage. J. Mater. Chem. 2012, 22, 23710. [CrossRef]

27. Hu, Z.; Zhang, L.; Wang, Z.; Yuan, Z. Bean dregs-derived hierarchical porous carbons as metal-free catalysts for efficient dehydrogenation of propane to propylene. J. Chem. Technol. Biotechnol. 2018, 93, 3410-3417. [CrossRef] 
28. Choi, I.; Jeong, H.Y.; Shin, H.; Kang, G.; Byun, M.; Kim, H.; Chitu, A.M.; Im, J.S.; Ruoff, R.S.; Choi, S.Y.; et al. Laser-induced phase separation of silicon carbide. Nat. Commun. 2016, 7, 13562. [CrossRef]

29. Oh, S.Y.; Yoo, D.I.; Shin, Y.; Kim, H.C.; Kim, H.Y.; Chung, Y.S.; Park, W.H.; Youk, J.H. Crystalline structure analysis of cellulose treated with sodium hydroxide and carbon dioxide by means of X-ray diffraction and FTIR spectroscopy. Carbohyd. Res. 2005, 340, 2376-2391. [CrossRef]

30. Kim, T.W.; Park, I.S.; Ryoo, R. A Synthetic Route to Ordered Mesoporous Carbon Materials with Graphitic Pore Walls. Angew. Chem. 2003, 115, 4511-4515. [CrossRef]

31. Gaddam, R.R.; Yang, D.; Narayan, R.; Raju, K.; Kumar, N.A.; Zhao, X.S. Biomass derived carbon nanoparticle as anodes for high performance sodium and lithium ion batteries. Nano Energy 2016, 26, 346-352. [CrossRef]

32. Yoon, D.; Kim, D.H.; Chung, K.Y.; Chang, W.; Kim, S.M.; Kim, J. Hydrogen-enriched porous carbon nanosheets with high sodium storage capacity. Carbon 2016, 98, 213-220. [CrossRef]

33. Cheng, J.; Gu, J.J.; Tao, W.; Wang, P.; Liu, L.; Wang, C.Y.; Li, Y.K.; Feng, X.H.; Qiu, G.H.; Cao, F.F. Edible fungus slag derived nitrogen-doped hierarchical porous carbon as a high-performance adsorbent for rapid removal of organic pollutants from water. Bioresour. Technol. 2019, 294, 122149. [CrossRef] [PubMed]

34. Sumathi, S.; Bhatia, S.; Lee, K.T.; Mohamed, A.R. Selection of best impregnated palm shell activated carbon (PSAC) for simultaneous removal of $\mathrm{SO}_{2}$ and $\mathrm{NO}_{\mathrm{x}}$. J. Hazard. Mater. 2010, 176, 1093-1096. [CrossRef] [PubMed]

35. Jiang, S.-F.; Ling, L.-L.; Chen, W.-J.; Liu, W.-J.; Li, D.-C.; Jiang, H. High efficient removal of bisphenol A in a peroxymonosulfate/iron functionalized biochar system: Mechanistic elucidation and quantification of the contributors. Chem. Eng. J. 2019, 359, 572-583. [CrossRef]

36. Lagergren, S. About the Theory of So-Called Adsorption of Soluble Substances. K. Sven. Vetensk. Handl. 1898, $24,1-39$.

37. McKay, H. Sorption of dye from aqueous solution by peat. Chem. Eng. J. 1998, 70, 115-124.

38. Langmuir, I. The adsorption of gases on plane surfaces of glass, mica and platinum. J. Am. Chem. Soc. 1918, 40, 1361-1403. [CrossRef]

39. Freundlich, H. Ueber die adsorption in loesungen. Z. Phys. Chem. 1907, 57, 385-470.

40. Shahzad, A.; Rasool, K.; Miran, W.; Nawaz, M.; Jang, J.; Mahmoud, K.A.; Lee, D.S. Two-Dimensional Ti ${ }_{3} \mathrm{C}_{2} \mathrm{~T}_{\mathrm{x}} \mathrm{MXene}$ Nanosheets for Efficient Copper Removal from Water. ACS Sustain. Chem. Eng. 2017, 5, 11481-11488. [CrossRef]

41. Khan, T.A.; Dahiya, S.; Ali, I. Use of kaolinite as adsorbent: Equilibrium, dynamics and thermodynamic studies on the adsorption of Rhodamine B from aqueous solution. Appl. Clay Sci. 2012, 69, 58-66. [CrossRef]

42. Liu, R.; Liu, Y.; Zhou, X.; Zhang, Z.; Zhang, J.; Dang, F. Biomass-derived highly porous functional carbon fabricated by using a free-standing template for efficient removal of methylene blue. Bioresour. Technol. 2014, 154, 138-147. [CrossRef]

43. Wang, B.; Zhai, Y.; Wang, T.; Li, S.; Peng, C.; Wang, Z.; Li, C.; Xu, B. Fabrication of bean dreg-derived carbon with high adsorption for methylene blue: Effect of hydrothermal pretreatment and pyrolysis process. Bioresour. Technol. 2019, 274, 525-532. [CrossRef]

44. Ahmed, M.J.; Okoye, P.U.; Hummadi, E.H.; Hameed, B.H. High-performance porous biochar from the pyrolysis of natural and renewable seaweed (Gelidiella acerosa) and its application for the adsorption of methylene blue. Bioresour. Technol. 2019, 278, 159-164. [CrossRef]

45. Islam, M.A.; Ahmed, M.J.; Khanday, W.A.; Asif, M.; Hameed, B.H. Mesoporous activated coconut shell-derived hydrochar prepared via hydrothermal carbonization- $\mathrm{NaOH}$ activation for methylene blue adsorption. J. Environ. Manag. 2017, 203, 237-244. [CrossRef] [PubMed]

46. Hameed, B.H.; Din, A.T.; Ahmad, A.L. Adsorption of methylene blue onto bamboo-based activated carbon: Kinetics and equilibrium studies. J. Hazard. Mater. 2007, 141, 819-825. [CrossRef] [PubMed]

47. Islam, M.A.; Ahmed, M.J.; Khanday, W.A.; Asif, M.; Hameed, B.H. Mesoporous activated carbon prepared from NaOH activation of rattan (Lacosperma secundiflorum) hydrochar for methylene blue removal. Ecotoxicol. Environ. Saf. 2017, 138, 279-285. [CrossRef] [PubMed]

48. Marrakchi, F.; Auta, M.; Khanday, W.A.; Hameed, B.H. High-surface-area and nitrogen-rich mesoporous carbon material from fishery waste for effective adsorption of methylene blue. Powder Technol. 2017, 321, 428-434. [CrossRef] 